\title{
The Design-Driven Living Lab: A New Approach to Exploring Solutions to Complex Societal Challenges
}

\author{
Rens Brankaert and Elke den Ouden
}

\author{
" If you ask customers what they want, they will tell you:" \\ 'Better, faster, and cheaper'- that is, better sameness, \\ not revolutionary change.
}

Guy Kawasaki

Marketing specialist, author, and venture capitalist

\begin{abstract}
In this study, we aimed to explore the potential of a design-driven living lab as an innovative approach to addressing societal challenges. This living lab incorporates design qualities such as exploration, open-ended results, and disruption. This approach was applied in three case studies within the context of dementia, each of which explored the impact of Qwiek.up - a media system that creates an ambient experience in a room through projection and sound. A cluster analysis of the results in the three case studies showed that the system has considerable potential for people with dementia, and possibly also for other groups. In addition, the design-driven approach led to new applications in care, improved functionality, and a broader design space. Our findings show that design-driven living labs can widen the scope of innovation and improve the value proposition of an innovative solution.
\end{abstract}

\section{Introduction}

With an ageing global population, there has been a substantial increase in the number of people living with dementia around the world (Wimo et al., 2003). Dementia severely hampers an affected individual's ability to live independently, and therefore they often have to rely on both formal and informal care (Prince et al., 2013). Thus, dementia is putting considerable pressure on healthcare costs and quality (Knapp et al., 2013). Furthermore, in Europe, healthcare budgets are being cut, including those for dementia care (Prince et al., 2013). The consequence is more accidents and a lower quality of life for people with dementia. However, the search for a solution is not straightforward, because dementia is an example of a "wicked problem" (Martin, 2009), meaning it requires a multi-perspective approach. The various stakeholders each have their own perspective and often contradictory needs (Brankaert et al., 2015).
Previous studies have revealed that living labs are suitable for tackling complex societal challenges (Liedtke et al., 2012). The living lab allows for different innovation methods, such as user evaluation, to be applied in collaboration with various stakeholders to find and evaluate new solutions (Brankaert, 2016). In a living lab, the validity of results is high because the methods are applied in a real-life context. Additionally, living labs involve various stakeholders, such as end users and both public and private parties. Indeed, living labs should involve end users in constructing meaningful innovation with and for them through co-creation (Almirall et al., 2012). Moreover, involving stakeholders with a market interest in living lab activities fosters successful innovation and increases market impact (Schuurman et al., 2016). Thus, this approach supports innovation in all phases of the lifecycle and enables a rapid route to market for innovative products (Leminen et al., 2012). 


\section{The Design-Driven Living Lab}

\section{Rens Brankaert and Elke den Ouden}

Although studies on living labs focus on evaluating solutions (Veeckman et al., 2013), finding innovative solutions requires going beyond the evaluation of existing offerings. Another aim of living labs is to look at problems creatively, and this aim can be achieved by adopting a design perspective. Design helps by identifying needs, conceptualizing, prototyping, implementing, and taking different perspectives (Krogstie, 2012). In addition, designers can explore, envision, and create more disruptive scenarios (Hummels \& Frens, 2011).

In the literature, it is suggested that living labs need outlines and structured, predefined goals (Korman et al., 2015). However, to deal with uncertainties in complex societal challenges, we need to take an open attitude to innovation in living labs. Moreover, different stakeholders can have different views and needs. There might be, for example, conflicting perspectives among business and care stakeholders concerning value versus revenue. To address such challenges, innovators need to apply integrative thinking and be able to hold two opposing ideas in their minds, thus creating a synthesis that contains elements of both while improving each. Designers have skills in this area, they seek factors that are not immediately obvious, and they tend to see a problem as a whole (Martin, 2007). Moreover, designers are able to generate creative resolutions in the form of new ideas.

With this article, we aim to present a new perspective on living labs by introducing the design-driven living lab and to investigate its potential by asking the following research question: How can we implement a designdriven living lab to explore innovation for dementia care challenges? We explored this question inductively by applying a design-driven living lab approach in three technology-based case studies.

\section{Methodology}

For this research, we conducted an explorative in-context study to investigate the effectiveness of a designdriven living lab approach. The living lab was positioned in a real-life environment, as opposed to a true lab environment, and we involved users as co-creators rather than subjects of study (Almirall et al., 2012). In addition, our design-driven focus allowed for openended insights into the context through an evaluation that was driven by the use of a "technology probe" (Gaver et al., 1999; Hutchinson et al., 2003), meaning that the participants were allowed to use the focal technology as they saw fit - without restrictions or prescriptions. Moreover, they were motivated to contribute to the value proposition: the promise of value to be de- livered by a product. They were encouraged to experiment with the technology and to reflect on their needs and the overall context through the technology. As such, the design-driven living lab approach goes beyond the mere evaluation of technology.

Through this design-driven approach, open-ended results can be generated in collaboration with the relevant stakeholders (Sanders \& Stappers, 2008). In our case study, people with dementia, care professionals, and a company were involved. In this way, a design-driven living lab can be used to navigate the "fuzzy" front-end of innovation, which is the initial phase of innovation where the context and target market segment are still unclear. The design-driven living lab involves design activities, such as identifying needs, conceptualizing, and taking different perspectives (Krogstie, 2012) within the living lab (Koskinen et al., 2011). We aim to use these activities in this study to address challenges in dementia care.

The three case studies in this article focused on the introduction of an innovative technical solution - the Qwiek.up system. By putting this device in the real-life contexts, we wished to gain an understanding of its contribution to dementia care, our understanding of dementia care itself, and potential new directions to take with the design. The results of the three case studies were compared and clustered to formulate insights into the design-driven living lab approach when applied in the context of dementia.

\section{Technology probe: Qwiek.up}

The technology probe used in the case studies is the Qwiek.up media system (Figure 1), which was developed by the company Qwiek (qwiek.eu). Research shows the importance of meaningful activities for good mental health and general wellbeing (Gold, 2013). The system addresses the problem of having insufficient suitable activities for people with dementia and therefore supports caregivers with their task. Through visual and audio output, this system creates a calming ambient experience for dementia patients in institutional care homes. The system comes with easy-to-use "experience modules", which simulate experiences such as a walk through the woods, looking up at a starry sky, visiting a farm, or viewing a custom slideshow of family photos with music. To use the system, the caregiver inserts an experience modules into the system, which then automatically initiates the corresponding experience. The system can transform a room into an experience by projecting images and video onto a wall or a ceiling (Figure 1). This device is a useful tool for professional caregivers in dementia 


\section{The Design-Driven Living Lab}

\section{Rens Brankaert and Elke den Ouden}
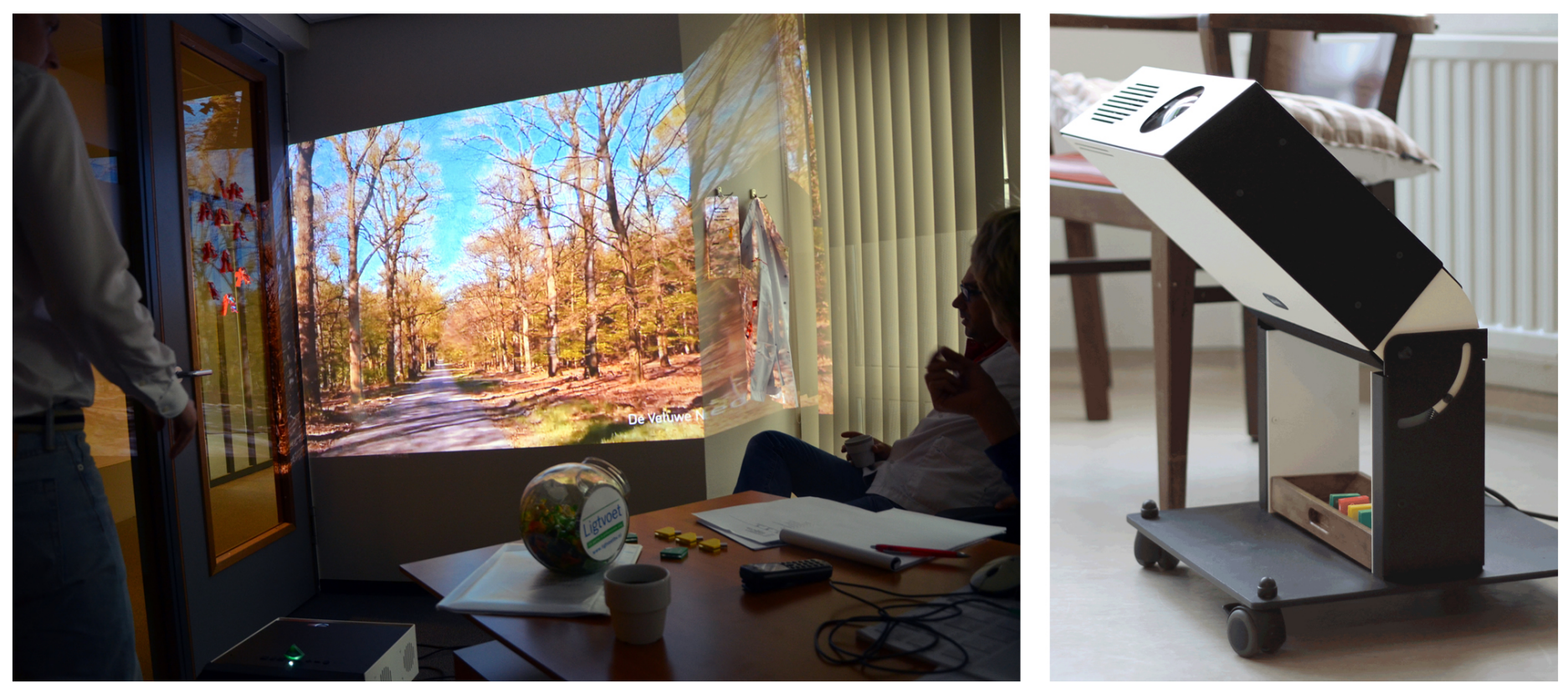

Figure 1. The Qwiek.up media system (right) depicting a walk through a forest on a regular wall (left)

care homes, where it can be used as a meaningful activity or as a non-pharmaceutical remedy for stress and agitation, which potentially reduces medicine use in care environments.

Several interventions that use immersive elements and sound have previously been investigated, such as for example "Snoezel(en) rooms" (tinyurl.com/go3v7as), which are controlled multisensory environments designed to create a soothing experience by stimulating the senses (Riley-Doucet \& Dunn, 2013). These earlier interventions, however, did not use familiar content for patients or were limited to a single room (Jakob \& Collier, 2015). The Qwiek.up system, in contrast, adds value because it is easy to use and is integrated into a wheeled stand that can easily be moved from room to room. Additionally, using a system that is beyond the prototyping phase allows the users to focus on how the technology functions within the context and the various applications it can include.

The main focus of the study was not to obtain feedback to further improve the system, but rather to explore how caregivers use the system in everyday practice. In this way, we aimed to explore the care context and reveal latent user needs. Additionally, this allowed us to gather new perspectives on the value proposition of the system. Nevertheless, insights relating to usability and the concept itself can be expected as a by-product. Therefore, our aim was consistent with our conceptual proposal of the design-driven living lab: to discover opportunities by introducing a new piece of technology in a real-life context.

\section{In-context evaluation of the Qwiek.up system}

Research on the Qwiek.up system was carried out in three care environments for people with dementia. Two studies were performed in a care home and the third one was performed within a dementia day programme where people with moderate dementia attended a facility for daily activities, yet still lived at home. The company behind the Qwiek.up system was involved in setting up this study and reflected with us on the outcomes. The characteristics of the three case studies are described in Table 1.

To carry out the study in the three locations, the following sequence of activities was adopted:

1. The system and research method were introduced to the staff.

2. Staff members were invited to use and experiment with the system during the study period. During this period, they recorded their experience with the system on an evaluation form.

3. After the study period, additional insights were collected during a focus group with the care professionals. 


\section{The Design-Driven Living Lab}

\section{Rens Brankaert and Elke den Ouden}

The evaluation form used to capture the experience requested the following details: a description of the experience, the length of engagement, its usefulness in the care context, and usability. To aggregate the findings in each of the case studies, we performed a cluster analysis with the retrieved data from both the form and the focus group (Koskinen, 2003). In this regard, the study had a dual role. We asked staff members to use the system and describe their experience, and then we instructed them to go beyond evaluation and experiment with using the device. This second role inspired new design directions and widened the value proposition. During the focus group, we encouraged them to reflect on their experience. Subsequently, the findings were aggregated into three topics to identify the role of the design-driven living lab in the innovation process. The insights gathered concerning both the system and the living lab approach were then shared with the company that created the system and interpreted with them.

\section{Results}

The three case studies delivered improvements to the system and demonstrated its value in dementia care. These results, from both the evaluation form and the focus group, are shown in Table 2. Especially in case studies 1 and 3 , the system was found to be a strong addition to formal care. The system was used as an activity for individuals and groups with dementia, and it increased the efficiency of care provision by giving the nurses more time to engage in their care practices. During the focus group with users from case study 3 , they even mentioned that the system could reduce the need for medication in some cases. In case study 2 , the system was less well received; however, here the professional caregivers showed less willingness to experiment with the system during their general care practices.

The cluster analysis of the data from both the evaluation forms and the focus group identified three clusters of topics: new insights concerning applications in care, the functionality of the system, and possible design extensions. The business perspective on each of these topics was added to these results. The results for each of these topics are described in the subsections that follow.

\section{Topic 1: Applications in care}

By using an open-ended evaluation, we found that, although the original target context (care homes) was suitable, a different context (day programmes) also shows great potential. The care professionals even indicated it that they felt it could be used for other condi- tions such as autism, because it provides a comfortable and recognizable ambience. In the case study 3 in particular, multiple purposes for the system were suggested. The system had benefits as a soothing individual activity as intended by the design. However, it was also used as an interactive group activity, as an activity for quieting down a group after lunch, and for one-on-one engagement and storytelling.

The attitude of the caregivers at the day programme centre might well have played an important role in this study. During the focus group, for example, we found that users in case study 3 were more engaged compared to those in the other case studies. They were very enthusiastic and they actively contributed more feedback than expected. They even wrote a thirty-page report in addition to the evaluation form to describe their experiences with the system in detail.

In summary, the users experimented with the device in all kinds of ways and discovered new purposes while doing so. This broadened the potential market for the system and also allowed us to discover latent needs in this care context. From a business perspective, the company reflected on the study that these insights added value to the system and opened potential future markets.

\section{Topic 2: Functionality}

We also discovered the need to make improvements to the Qwiek.up system in terms of functionality, technology, and usability. For instance, the projector sometimes malfunctioned, and the company should prioritize fixing such technical issues. Additionally, some of the care professionals in case study 1 found the system hard to use. They suggested making the system's physical controls easier to use or adding a remote control. Furthermore, in some of the experience modules, the music that was preselected by the company to fit with certain videos did not match, resulting in a conflicting experience.

The company is already improving some elements of the product based on this feedback on its functionality and is investigating the potential of adding a remote control or other ways of interacting with the system by both the care professionals and the patients.

\section{Topic 3: Design extensions}

Opportunities arose in all three case studies for improving the conceptual design of the Qwiek.up. In case study 1 , for example, the potential of adding interactivity was discussed to allow those with dementia to have 


\section{The Design-Driven Living Lab}

Rens Brankaert and Elke den Ouden

Table 1. Context description of the three case studies

\begin{tabular}{llll}
\hline & Case Study 1 & Case Study 2 & Case Study 3 \\
\hline Country & Netherlands & Germany & Germany \\
\hline Care context & Care home & Care home & Day programme \\
\hline Dementia profile & Advanced & Advanced & Moderate \\
\hline Care professionals & 6 & 4 & 3 \\
\hline Residents & 14 & 11 & 28 \\
\hline Study period & 29 days & 33 days & 35 days \\
\hline Evaluation records & 6 & 7 & 15 \\
\hline
\end{tabular}

Table 2. Evaluative results concerning the Qwiek.up system in the three case studies

\begin{tabular}{|c|c|c|c|}
\hline & Case Study 1 & Case Study 2 & Case Study 3 \\
\hline General response to the system & Positive & Moderate to negative & Very positive \\
\hline Experience modules & $\begin{array}{l}\text { Natural modules were } \\
\text { preferred (e.g., Aquarium } \\
\text { and Forest) }\end{array}$ & $\begin{array}{l}\text { Module of starry sky was } \\
\text { used to help individuals to } \\
\text { sleep better; others were } \\
\text { less appreciated. }\end{array}$ & $\begin{array}{l}\text { Residents responded well to } \\
\text { the natural modules; in } \\
\text { some cases, there was a } \\
\text { mismatch between image } \\
\text { and music in the modules. }\end{array}$ \\
\hline Technical difficulties & $\begin{array}{l}\text { The projector had some } \\
\text { issues with finding focus }\end{array}$ & $\begin{array}{l}\text { Physical controls on the } \\
\text { system were considered } \\
\text { difficult to use. }\end{array}$ & None \\
\hline Experience & $\begin{array}{l}\text { Various use cases were } \\
\text { found such as group } \\
\text { sessions (max. } 30 \text { minutes) } \\
\text { and individual use. }\end{array}$ & $\begin{array}{l}\text { Positive use for one-on- one } \\
\text { session and sleep sessions; } \\
\text { other uses were not } \\
\text { explored. }\end{array}$ & $\begin{array}{l}\text { Many unexpected uses such } \\
\text { as calming down a group } \\
\text { after lunch and association } \\
\text { games with a group. }\end{array}$ \\
\hline Focus group results & $\begin{array}{l}\text { System usefulness and } \\
\text { application varied from } \\
\text { person to person, but some } \\
\text { users were engaged for 3-4 } \\
\text { hours at a time. Interactivity } \\
\text { would contribute to the } \\
\text { experience. }\end{array}$ & $\begin{array}{l}\text { Care professionals were not } \\
\text { very fond of the system. } \\
\text { However, the system was } \\
\text { used as a conversation } \\
\text { starter once, which was } \\
\text { deemed positive. }\end{array}$ & $\begin{array}{l}\text { Care professionals were } \\
\text { enthusiastic about the } \\
\text { system; it could easily } \\
\text { become a standard tool in } \\
\text { day programmes. The } \\
\text { system was used for many } \\
\text { purposes in various ways. }\end{array}$ \\
\hline
\end{tabular}




\section{The Design-Driven Living Lab}

\section{Rens Brankaert and Elke den Ouden}

an even more engaging experience. In addition, this means that the system could cater to a wider spectrum of users, and that those, for example, in a less advanced state of dementia might be more engaged with the system with the addition of interactive aspects. This extension could also increase the engagement of people with dementia by stimulating play (Anderiesen et al., 2015). In addition, in case studies 2 and 3, we found that the selection of experience modules should be increased. The selection is currently limited and more options would be desirable.

Currently, additional experience modules are being developed and released by the company that created the system. In this way, they are able to quickly broaden their offering and improve the overall experience of the system. For more radical conceptual improvements, for example adding interactive games, development will take longer. However, based on the findings in this study, the company is already developing new conceptual extensions to their system.

\section{Discussion}

Over the course of three case studies, we demonstrated the potential of a design-driven approach to living labs. Earlier living lab studies have included active user involvement, for example through co-creation (Sanders \& Stappers, 2008). However, by adding design characteristics such as exploration and dealing with uncertainty, living labs can be refocused to better deal with complex problems such as dementia care. In this study, we contributed to answering our research question: How can we implement a design-driven living lab to explore innovation for dementia care challenges? The design-driven approach allowed us by actively involving care professionals to broaden the value proposition of the Qwiek.up system, explore the context of dementia care, repurposing the design, and find new opportunities for innovation.

The design-driven living lab approach uses a fully operational system that is presented as a technology probe. This is a high-quality product - rather than a functional prototype - that can be used to explore latent needs, new uses, and opportunities for innovation beyond the evaluation of the current product. This different perspective on putting innovative systems in a real-life context is based on design approaches such as needsfinding, conceptualization, and opportunity seeking (Krogstie, 2012). Today's technology enables the creation of high-quality products in a shorter amount of time, making it possible for in-context studies to influence the value proposition and market release specifications - resulting in shorter innovation cycles. This approach enables fast learning, for example, as was apparent in the redesign of the experience modules or the interface of the Qwiek.up system. This work can be done in a short amount of time, leading to a market release that improves the product offering. Nevertheless, for larger design improvements, such as adding interactivity or answering new use environments such as for children with autism, follow-up design processes are needed, which will take longer to conduct.

Involvement of users in the design-driven living lab is inspired by co-creation (Bergvall-Kåreborn \& Ståhlbröst, 2009). However, instead of focusing co-creation efforts in a controlled session, we apply a co-creation perspective during the entire in context study. This allowed participants greater freedom in using the concept, and it allowed us to be more open in interpreting the results. As a result, the participants maintain an open attitude throughout the study, allowing additional insights to emerge such as, for example, new applications or opportunities for meaningful activities in a dementia care context. This was notably demonstrated during the third case study, in which the system was clearly used in an unrestricted and explorative way by the users (Valk et al., 2012). In this case, the users felt they had the freedom to use the system as they saw fit and experimented with it in their specific care settings. This approach also allowed the company to find new uses for the system and orient towards new opportunities in care innovation.

Navigating the early stages of innovation often seems challenging, and this is also the case for living lab practices. However, the inclusion of design skills, such as dealing with opposing perspectives, offers concrete tools to do this (Koskinen et al., 2011). In this study, we have shown that an explorative approach with technology probes can enable the identification of needs beyond the original value proposition and inspire new innovative solutions. The suggestion to facilitate play within the system, for example, allows the company to widen the market impact of the system.

\section{Further research}

This article presented an initial application of the design-driven living lab. However, the exact characteristics of this phenomenon are unclear and need to be investigated in greater depth. For example, the system used in this study was arguably already purposed for a 


\section{The Design-Driven Living Lab}

Rens Brankaert and Elke den Ouden

care context and did not allow for an open-ended exploration in the same context. The effect of different development levels of prototypes/products needs to be further evaluated.

In addition to our insights, we found some limitations in our application of the design-driven living lab approach. We see that, based on our three case studies, there is scope to improve the evaluation method and the design-driven approach. There are, as yet, no best practices for design-driven living labs, and the evaluation methods we used had some limitations. Some users even stopped filling it in regularly after a week into the study because they felt it was too boring. The participants might need more motivation to explore the new technology and more in-depth evaluation forms with fewer intervals might maintain interest. Additionally, alternative ways to capture an open-ended experience, such as diary studies, might be applied. The report provided by the users in case study 3 provided much richer insights into their experience. Also, the more open approach of the focus group methodology made it possible to do more than just capturing experiences and, in addition, allowed for discussion of other topics, such as design opportunities. An important aspect we discovered is the attitude of the users, as we saw in case study 3 , where it was reflected in the participants' willingness to experiment. To clarify this aspect, further research is needed on methodologies that can be used to engage users in open and explorative studies as part of a design-driven living lab.

In the future, we aim to create more diverse forms of the design-driven living lab in order to explore its potential for innovation. In this regard, we aim to target the complexity of other societally relevant challenges and emphasize the inclusion of more diverse stakeholders.

\section{Conclusions}

Over three case studies, we demonstrated the potential of a design-driven living lab approach. Participants were invited to openly and freely use a new system in their professional context of caring for people with dementia. The results show that the type of feedback obtained can indeed go well beyond an evaluation of a particular design, however, this still needs to be explored further. New insights can be obtained for repurposing the design and defining new value propositions.
A design-driven way of performing a living lab makes it possible to extend the boundaries of the approach from evaluation to include exploring innovative solutions. It shows that there is potential for more disruptive, openended development of innovation.

In this way, we succeeded in implementing a first iteration of a design-driven living lab. It allowed us to explore both the method and the contexts in which the intervention was applied. The evaluation results are more open-ended, with more room for input from the various stakeholders. The intervention was not evaluated on its effectiveness but rather as an opportunity and, as a result, it strengthened the value proposition and the business case. This was evident in the response by the company, which has included our findings in their system and development processes. Overall, our approach shows that there is potential for navigating the early stages of future innovation processes with developed products designed to address complex societal challenges.

\section{About the Authors}

Rens Brankaert is an Assistant Professor working on design for "Active \& Healthy Ageing" within the Business Process Design group in the Department of Industrial Design at Eindhoven University of Technology (TU/e) in the Netherlands. He received his PhD early in 2016 for work related to design for people with dementia involving the application of living labs. In this work, he aimed to build a bridge between a design-based approach and current healthcare practices.

Elke den Ouden is based at the Innovation, Technology and Entrepreneurship Management Group in the Department of Industrial Engineering and Innovation Sciences at Eindhoven University of Technology (TU/e) in the Netherlands. As a TU/e Fellow and Strategic Director of TU/e LightHouse, she forges links between research and industry. Her long history at Philips, including in the role of group leader, has provided her with the network and expertise needed to do perform her current role. Elke operates as the TU/e living lab expert and regularly publishes on this topic. 


\section{The Design-Driven Living Lab}

\section{Rens Brankaert and Elke den Ouden}

\section{References}

Almirall, E., Lee, M., \& Wareham, J. 2012. Mapping Living Labs in the Landscape of Innovation Methodologies. Technology Innovation Management Review, 2(9): 12-18.

http://timreview.ca/article/603

Anderiesen, H., Scherder, E., Gossens, R., Visch, V., \& Eggermont, L. 2015. Play Experiences for People with Alzheimer's Disease. Interactive Journal of Design, 9(2): 156-165.

Bergvall-Kåreborn, B., \& Ståhlbröst, A. 2009. Living Lab: An Open and Citizen-Centric Approach for Innovation. International Journal of Innovation and Regional Development, 1(4): 356-366. http://dx.doi.org/10.1504/IJIRD.2009.022727

Brankaert, R. 2016. Design for Dementia: A Design-Driven Living Lab to Involve People Living with Dementia and their Context. Eindhoven, The Netherlands: University of Technology Eindhoven.

Brankaert, R., den Ouden, E., \& Brombacher, A. 2015. Innovate Dementia: The Development of a Living Lab Protocol to Evaluate Interventions in Context. Info, 17(4): 40-52. http://dx.doi.org/10.1108/info-01-2015-0010

Gaver, B., Dunne, T., \& Pacenti, E. 1999. Design: Cultural Probes. Interactions, 6(1): 21-29.

https://doi.org/10.1145/291224.291235

Gold, K. 2013. But Does It Do Any Good? Measuring the Impact of Music Therapy on People with Advanced Dementia. Dementia, 13(2): 258-264.

https://doi.org/10.1177/1471301213494512

Hummels, C., \& Frens, J. 2011. Designing Disruptive Innovative Systems, Products and Services: RTD Process. In D. A. Coelho (Ed.), Industrial Design-New Frontiers: 147-172. Rijeka, Croatia: InTech.

http://dx.doi.org/10.5772/22580

Hutchinson, H., Mackay, W., Westerlund, B., Bederson, B. B., Druin, A., Plaisant, C., Lafon-Beaudouin, M., Conversy, S., Evans, H., Hansen, H,. Roussel, N,. \& Eiderbäck, B. 2003. Technology Probes: Inspiring Design For and With Families. In Proceedings of the SIGCHI Conference on Human Factors in Computing Systems: 17-24, April 5-10, Ft. Lauderdale, FL.

http://doi.org/10.1145/642611.642616

Jakob, A., \& Collier, L. 2015. How to Make a Sensory Room for People Living with Dementia - Developing Design Guidance for Health Care Practitioners. Paper presented at the Third European Conference on Design4Health 2015, Sheffield, UK.

Knapp, M., Iemmi, V., \& Romeo, R. 2013. Dementia Care Costs and Outcomes: A Systematic Review. International Journal of Geriatric Psychiatry, 28(6): 551-561. http://dx.doi.org/10.1002/gps.3864

Korman, M., Weiss, P. L., \& Kizony, R. 2015. Living Labs: Overview of Ecological Approaches for Health Promotion and Rehabilitation. Disability and Rehabilitation, 38(7): 613-619. http://dx.doi.org/10.3109/09638288.2015.1059494
Koskinen, I. 2003. User-Generated Content in Mobile Multimedia: Empirical Evidence from User Studies. In Proceedings of the 2003 International Conference on Multimedia and Expo (ICME '03), 2(3): 645-648.

Koskinen, I., Zimmerman, J., Binder, T., Redström, J., \& Wensveen, S. 2011. Design Research Through Practice From the Lab, Field, and Showroom. Waltham, MA: Morgan Kaufmann.

Krogstie, J. 2012. Bridging Research and Innovation by Applying Living Labs for Design Science Research. In C. Keller, M. Wiberg, P. J. Ågerfalk, \& J. S. Z. Eriksson Lundström (Eds.), Nordic Contributions in IS Research: 161-176. Berlin: Springer-Verlag Berlin Heidelberg. http://dx.doi.org/10.1007/978-3-642-32270-9_10

Leminen, S., Westerlund, M., \& Nyström, A.-G. 2012. Living Labs as Open-Innovation Networks. Technology Innovation Management Review, 2(9): 6-11. https://timreview.ca/article/602

Liedtke, C., Welfens, M. J., Rohn, H., \& Nordmann, J. 2012. LIVING LAB: User-Driven Innovation for Sustainability. International Journal of Sustainability in Higher Education, 13(2): 106-118. http://dx.doi.org/10.1108/14676371211211809

Martin, R. 2007. Opposable Mind: How Successful Leaders Win Through Integrative Thinking. Boston, MA: Harvard Business School Press Books.

Prince, M., Prina, M., \& Guerchet, M. 2013. World Alzheimer Report 2013 - Journey of Caring: An Analysis of Long-Term Care for Dementia. London: Alzheimer's Disease International.

Riley-Doucet, C. K., \& Dunn, K. S. 2013. Using Multisensory Technology to Create a Therapeutic Environment for People with Dementia in an Adult Day Center: A Pilot Study. Research in Gerontological Nursing, 6(4): 225-233. http://dx.doi.org/10.3928/19404921-20130801-01

Sanders, E., \& Stappers, P. J. 2008. Co-Creation and the New Landscapes of Design. CoDesign, 4(1): 5-18. http://dx.doi.org/10.1080/15710880701875068

Schuurman, D., Marez, L. De, \& Ballon, P. 2016. The Impact of Living Lab Methodology on Open Innovation Contributions and Outcomes. Technology Innovation Management Review, 1(6): 7-16. http://timreview.ca/article/956

de Valk, L., Rijnbout, P., Bekker, T., Eggen, B., \& Schouten, B. 2012. Designing for Playful Experiences in Open-Ended Intelligent Play Environments. In Proceedings of the IADIS International Conference Game and Entertainment Technologies 2012 (GET '12): 3-10. IADIS Press.

Veeckman, C., Schuurman, D., Leminen, S., \& Westerlund, M. 2013. Linking Living Lab Characteristics and Their Outcomes: Towards a Conceptual Framework. Technology Innovation Management Review, 3(12): 6-15. http://timreview.ca/article/748

Wimo, A., Winblad, B., Aguero-Torres, H., \& von Strauss, E. 2003. The Magnitude of Dementia Occurrence in the World. Alzheimer Disease and Associated Disorders, 17(2): 63-67. 